\title{
Rede e subjetividade na filosofia francesa contemporânea ${ }^{1}$
}

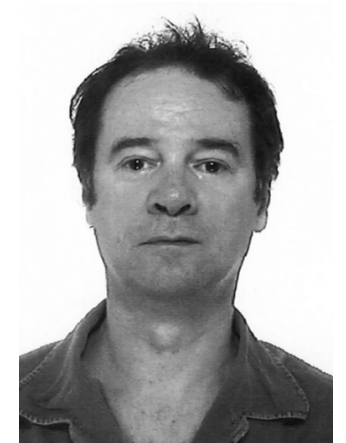

\section{André Parente}

Departamento de Teoria da Comunicação - Escola de Comunicação - Universidade Federal do Rio de Janeiro, Rio de Janeiro, Brasil aparente@superig.com.br

\section{Resumo}

$\mathrm{O}$ presente artigo apresenta três diferentes visões de rede na filosofia francesa contemporânea, em particular no pensamento de Paul Virilio, Michel Foucault e Bruno Latour. O que chamamos, junto com Bruno Latour, de redes de transformações são agenciamentos sociotécnicos que estão alterando as condições da experiência e produzindo novas formas de subjetividade. As redes são figuras empíricas da ontologia do presente, figuras que nos permitem pensar o campo da comunicação como problema estrutural da contemporaneidade.

\section{Palavras-chave}

Rede, novas tecnologias de comunicação, filosofia, ciberespaço

\section{Introdução}

As redes são por demais reais. Para verificar nossa dependência das redes basta imaginar uma viagem a um lugar remoto onde tudo o que compóe a galáxia emaranhada de redes e serviços que alimentam os nossos ecossistemas móveis e imóveis vai nos fazer falta: a água, a comida, a eletricidade, os meios de comunicação, os meios de transporte etc.

Elas sempre tiveram o poder de produção de subjetividade e do pensamento. Mas era como se as redes fossem dominadas por uma hierarquização social que nos impedia de pensar de forma rizomática. Com o enfraquecimento da ordem de leitura (Chartier, 1994) do Estado contemporâneo face aos interesses do capital internacional, e com a emergência do indivíduo e dos dispositivos de comunicação, aparece aqui e ali uma reciprocidade entre as redes e as subjetividades, como se, ao se retirar, a hierarquização social deixasse ver não apenas uma pluralidade de pensamentos, mas o fato de que pensar é pensar em rede.

As redes tornaram-se ao mesmo tempo uma espécie de paradigma e de personagem principal das mudanças em curso justo no momento em que as tecnologias de comunicação e de informação passaram a exercer um papel estruturante na nova ordem mundial. A sociedade, o capital, o mercado, o trabalho, a arte, a guerra são, hoje, definidos em termos de rede. Nada parece escapar às redes, nem mesmo o espaço, o tempo e a subjetividade. A filosofia francesa contemporânea vem dando uma enorme contribuição ao pensamento das redes, e não é à toa que, no livro Tramas da Rede (PARENTE, 2005), ela ocupa um lugar privilegiado. 
Não se trata de explicar os conceitos dos grandes filósofos franceses contemporâneos, nem mesmo de evidenciar qualquer filiação entre eles, mas de mostrar que alguns de seus conceitos - rizoma (DELEUZE et al., 1995), estética da desaparição (BAUDRILLARD, 1991; VIRILIO), último veículo (VIRILIO), redes de transformação (LATOUR et al., 2004), heterotopia (FOUCAULT, 1994), pantopia (SERRES, 1998) - formam um campo conceitual que pode ser utilizado para fundar uma verdadeira teoria das novas tecnologias como rede de comunicação biopolítica. Um dia, os teóricos e historiadores da comunicação vão se dar conta de que pensar em rede não é apenas pensar na rede, que ainda remete à idéia de social ou à idéia de sistema, mas é, sobretudo, pensar a comunicação como lugar da inovação e do acontecimento, daquilo que escapa ao pensamento da representação. Neste dia, a comunicação terá se tornado, para além de suas tecnologias, fundamento.

$\mathrm{Na}$ França, o interesse pela representação em rede surgiu nos anos 1960 na filosofia e nas ciências humanas, em trabalhos que estabeleciam uma relação complexa e variável com o estruturalismo. O pensamento reticular resultante estendia uma face para as matrizes ou estruturas gerais (mas que se impunham como uma forma $a$ priori) e uma outra para um empirismo radical.

Na verdade, muitos dos filósofos e teóricos franceses contemporâneos estão de acordo com o fato de que as máquinas infocomunicacionais estariam engendrando profundas transformações nos dispositivos de produção das subjetividades.

\section{O último veículo}

Virilio produziu uma série de ensaios sobre o espaço em sua relação com a velocidade dos veículos de transporte e os veículos audiovisuais. Os veículos móveis e audiovisuais transformam radicalmente as nossas relações com o espaço. Por um lado, o espaço estaria se transformando em função da aparição de novos meios de transporte e de comunicação. O espaço é outro se vamos a cavalo, de carro ou de avião, se utilizamos a escrita ou a telecomunicação. Tudo se passa como se o espaço do enclausuramento estivesse cedendo lugar ao ciberespaço, o qual, segundo Virilio, significa o fim do espaço, a sua anulação mesma: se o final do século XIX e o início do século XX assistiram ao advento dos veículos ferroviário, rodoviário e aéreo, o nosso fim de século tem assistido a grandes mudanças com o advento do veículo audiovisual e veículos de telepresença: a televisão, a videoconferência, as redes telemáticas, o ciberespaço.

O espaço, os acontecimentos, as informações e as pessoas são condicionados, cada vez mais, pela telecomunicação, assim como a transparência do espaço de nossos percursos tende a ser substituída pelas articulações do veículo audiovisual, último horizonte de nossos trajetos, cujo modelo mais perfeito é o ciberespaço. Segundo Virilio, chegaremos ao tempo em que não haverá mais campo de tênis, mas um campo virtual; não haverá mais passeio de bicicleta, mas exercícios em um home-trainer; não haverá mais guerra, mas videogame; não haverá mais astronautas, mas telerrobôs: o espaço não se estenderá mais. O momento de inércia sucederá ao deslocamento contínuo no dia em que todos os deslocamentos se concentrarem em um só ponto fixo, em uma imobilidade que não é mais a do não-movimento, mas a da ubiqüidade potencial, a da mobilidade absoluta que anula seu próprio espaço à força de o tornar tão transparente. Virilio chegou mesmo, a exemplo do Flâneur, de Benjamin, a criar um personagem conceitual, o paralítico tecnologizado, atingido pela inércia polar dos veículos ciberespaciais.

Para nós, o ciberespaço é apenas o mais novo espaço de jogos da humanidade, que inaugura uma nova arquitetura, a arquitetura da informação. De acordo com Walter Benjamin, se cada sociedade tem seus tipos de máquinas, é porque elas são o correlato de expressões sociais capazes de fazê-las lhes fazer nascer e delas se servir como verdadeiros órgãos da realidade nascente.

A idéia de que o horizonte de nossos trajetos é o ciberespaço, o último veículo, ligado em rede e podendo ver e agir a distância, ponto de concentração de todo o espaço anulado pela ubiqüidade absoluta, é, no mínimo, uma utopia tecnológica e um contra-senso históricocultural. Utopia tecnológica que supõe que as diferentes técnicas e mídias possam se fundir em uma interface única cada vez mais transparente que representaria uma convergência de todas as interfaces. Além disso, é desconhecer a história da técnica, uma vez que toda a história da técnica - da invenção do fogo à invenção da roda, passando pela cadeira, automóvel, elevador e escada rolante - leva a uma sedentarização do corpo.

Contra-senso cultural que supõe que a cultura possa existir sem a natureza e sem a técnica. Que inteligência seria apenas a de nossos cérebros, sem ser também a de nossas línguas ou a da luminescência do universo? Onde estão a natureza, a cultura e a técnica aqui? Onde está o real, ou melhor, o virtual, quando se diz que o universo está escrito nessa língua que é a geometria? Onde está o virtual, ou melhor, o real, quando se diz que o nosso olho é produzido pela luz do sol? Como conciliar a geometria (o inteligível) e a cor (o sensível) nessa imagem que não pára de se algebrizar, ou melhor, de se temporalizar, desde a Tavoletta de Brunelleschi?

Cabe aqui a pergunta: onde se encontram os fenômenos? Fora das redes, dirão os realistas. Dentro das redes e linguagens, dirão os idealistas. Como disse Latour em seu artigo: "Infelizmente os fenômenos circulam através do conjunto que compõe as redes, e é unicamente sua circulação que nos permite verificá-los, assegurá-los, validá-los”.

\section{Espaço: heterotopia e pantopia}

Claro que o ciberespaço ou o espaço da informação não significa a anulação do espaço, mas apenas a realização tecnológica do espaço topológico, o espaço da justaposição do próximo e do longínquo, do simultâneo. Ou seja, com o ciberespaço, viveremos cada vez mais o espaço como sendo espaço das relações de vizinhança, espaço de conexões, heterotópico e pantópico. 
FOUCAULT (1994), em uma conferência intitulada "Espaços Outros", fez uma breve história do espaço no Ocidente, para nela situar as questões relançadas pelo processo de dessacralização ocasionado pelo espaço contemporâneo, espaço da informação, das memórias estocásticas e das redes. Segundo ele, ao contrário do que possa parecer, a nossa época é obcecada pelo espaço: vivemos a época do simultâneo, da justaposição, do próximo e do longínquo.

FOUCAULT (1994) descreve três tipos de espaço. Na Idade Média, o espaço de localização era um conjunto de lugares hierarquizados. Este espaço entra em crise com Galileu e a ciência moderna. A descoberta mais importante de Galileu não foi a de que a terra girava em torno do sol, mas o fato de ter constituído um espaço infinitamente aberto. Ou seja, o lugar das coisas são apenas pontos em seu movimento. O espaço como extensão substitui a localização. Em nossos dias, o espaço torna-se topológico: passa a ser definido pelas relações de vizinhança entre os pontos e elementos, e forma séries, tramas, grafos, diagramas, redes.

Para SERRES (1998), a relação de mistura e conexão criada pela rede forma uma pantopia: todos os lugares em um só lugar e cada lugar em todos os lugares. O termo pantopia possui uma lógica muito próxima da do espaço heterotópico, o qual aponta para o desejo da reunião de todos os lugares em um só lugar, como em um museu de história natural, que dispõe lado a lado pássaros que pertencem a lugares e épocas distintas. É exatamente esse local de acumulação do mesmo enquanto outro, que nos leva a dizer, quando estamos na rede, que estamos aqui e lá ao mesmo tempo, e que caracteriza a heterotopia pósmoderna. A heterotopia está longe de ser ameaçada pelo espaço da hipermídia e da rede, cuja lógica é a mesma: co-presença topológica, tramas das redes.

Se a experiência do ciberespaço está destinada a nos transformar verdadeiramente, não é porque ela vai substituir a realidade por uma realidade cibernética, uma realidade simulada, mas porque o ciberespaço coloca em prática e potencializa o processo de heterotopia descrito por FOUCAULT (1994).

\section{As redes de transformação}

Tomemos como exemplo a imagem de rede que nos fornece Latour: uma coleção de pássaros empalhados em uma estante de um museu de história natural produz uma heterotopia que permite ao pesquisador compará-los e analisá-los longe da confusão dos ecossistemas naturais em que se encontravam. A coleção é como o centro, o nó, o campo gravitacional que produz um novo arranjo entre o próximo e o longínquo: pássaros "locais" são justapostos a pássaros da mesma espécie trazidos do mundo inteiro. Comparada com a situação inicial, em que cada animal vivia em seu ecossistema singular, trata-se de uma perda e uma redução enorme, pois seria impossível reproduzir essa realidade. Mas, se comparada com a confusão de uma floresta tropical, de onde dificilmente se poderia deduzir um novo saber, que amplificação extraordinária! $\mathrm{Na}$ verdade, essa estante é, como veremos abaixo, não apenas a heterotopia que exprime a topologia das redes - sejam elas mais ou menos centradas, mais ou menos velozes, mais ou menos extensas - que os computadores e as redes telemáticas vão potencializar (a descentralização do computador não rompe com a lógica da heterotopia, pois é apenas um efeito da sua velocidade), mas a lógica dos algoritmos fractais, dimensões intermediárias ou híbridos entre as paisagens singulares e os modelos da ciência.

O trabalho de Latour e de Callon, mais ainda do que o de LÉVY (1993), leva-nos a perceber que as tecnologias de informação e comunicação podem ser entendidas como tecnologias da inteligência menos por projetar ou exteriorizar a riqueza e complexidade dos processos cognitivos do que por revelar o quanto sua complexidade deriva não apenas da riqueza de nossos sentidos e faculdades, mas também dos objetos, suportes, dispositivos e tecnologias que nos circundam e compõem uma rede sociotécnica de grande complexidade. O que está em jogo é menos a função protética da tecnologia - que, de fato, muitas vezes serve como uma extensão de habilidades cognitivas dadas (uma prótese que prolonga e potencializa nosso pensamento e seus processos de tratamento e de transmissão das informações) - do que um processo contínuo de delegação e distribuição das atividades cognitivas que formam uma rede com os diversos dispositivos não-humanos.

Por que transformar o mundo em informação? Porque a informação permite resolver de forma prática - por meio de operações de seleção, de extração, de redução e de inscrição - o problema da presença e da ausência em um lugar. A informação estabelece uma interação material entre o centro e a periferia, o que deve ser produzido para que a ação a distância sobre ela seja mais eficaz. Como disse Latour em seu artigo:

\begin{abstract}
"desde que uma informação goza das vantagens do inscrito do cálculo, da classificação, do superposto, disto que se pode inspecionar com o olhar, ela se torna comensurável com todas as outras inscrições pertencentes a realidades até então estranhas umas às outras. Compreendemos melhor, hoje, este fenômeno, porque utilizamos todos computadores e redes hipertextuais que nos permitem combinar, traduzir, integrar desenhos, textos, fotografias e gráficos, até então separados no espaço e no tempo." (LATOUR, 2004)
\end{abstract}

A rede é, portanto, a imobilidade necessária para recolher o que deve nela transitar. Consideremos a topologia especial dessas redes. Redes de transformação fazem chegar aos centros de cálculos, por uma série de deslocamentos, um número cada vez maior de informações. No início, o computador surgiu como uma ferramenta para ajudar o homem a processar o aumento exponencial de informações que deveriam ser tratadas. Imagine o trabalho que teríamos hoje se não dispuséssemos de computador para calcular os índices econômicos e socioculturais.

As informações circulam, mobilizando toda a rede de intermediários que se estende do centro à periferia, e, ao fazê-lo, criam uma espécie de tensão que mantém a rede coesa. A tensão é um dos parâmetros da rede, ao 
lado do fluxo, da velocidade e da intensidade. É apenas quando seguimos os traços da circulação de informação, diz Latour em seu artigo, que atravessamos a distinção usual entre os signos e a realidade: "não navegamos apenas no mundo, mas também nas diversas matérias de expressão".

A ciência e a tecnologia são, para Latour, uma megarrede heterogênea que mobiliza homens e coisas e cria um campo de tensão e forças que os hibridiza. É impossível compreender qualquer rede sem conhecer as instituições, os veículos materiais e os atores que intermedeiam a relação entre periferia e centro das redes. $\mathrm{O}$ conjunto das redes de transformação e seus centros dotam aqueles que os dominam de uma vantagem enorme, na medida em que eles estão ao mesmo tempo afastados dos lugares e interligados aos fenômenos por uma série reversível de transformações. Os centros da rede nada mais são do que os espaços onde a intensidade heterotópica é maximizada e pode ser capitalizada como tantas ações potenciais sobre o mundo.

Se quisermos compreender como certas visões de mundo se impõem e se tornam dominantes, como nos apegamos às coisas, aos procedimentos, a certos comportamentos, devemos analisar o processo de transformação do mundo em informação nas redes, sejam elas quais forem. A verdade sobre Deus, a verdade sobre a natureza e uma certa tendência na arte não existem fora das redes em que circulam, como se fossem fenômenos que falariam por si.

A ciência não se aplica a partir das idéias de seus gênios. A ciência replica-se, como o social, mas para que isso ocorra é preciso investimentos enormes. É verdade que as tecnologias apenas tornam mais visível a infraestrutura da rede da ciência:

"Quando medimos as informações em bits e bauds, quando somos assinantes de um banco de dados, quando, para agir e pensar, nos conectamos a uma rede de comunicação, é mais difícil continuar vendo o pensamento científico como um espírito flutuando sobre as águas. Hoje a razão, que nada tem de natural, se assemelha muito mais a uma rede de comunicação, uma rede de telemática do que às idéias platônicas". (LATOUR, 2004)

\section{Do Rizoma à Autopoiesis: rede e subjetividade}

Como Virgínia Kastrup (KASTRUP, 2004) mostrou muito bem, as redes de transformações de Latour são uma versão empírica e atualizada do rizoma que serve para pensar a criação dos híbridos. Para Latour, de fato, os híbridos emergem da rede como intermediários entre os elementos heterogêneos objetivos e subjetivos, sociais e tecnológicos, saberes e coisas, inteligências e interesses, em que as matérias e as subjetividades são trabalhadas, forjadas, fundidas sem o controle dos métodos ditos objetivos da ciência.

O conceito de rizoma criado por Deleuze e Guattari é um conceito fractal, que nos leva a pensar em uma dimensão intermediária que nos ajuda a superar as di- cotomias do inteligível e do sensível, do discursivo e do extradiscursivo, do sujeito e do objeto.

O conceito de rizoma foi criado por Deleuze a partir da concepção que Barthes tinha do livro, e foi utilizado por LÉVY (1993) como um novo paradigma para entender as redes hipertextuais e as interfaces dinâmicas computacionais.

A descrição que BARTHES (1992) faz do texto em $S / Z$ é a descrição que contém todos os princípios fundamentais do hipertexto: a rede não tem unidade orgânica; nela abundam muitas redes que atuam sem que nenhuma delas se imponha às demais; ela é uma espécie de galáxia mutante, com diversas vias de acesso, sem que nenhuma delas possa ser qualificada como principal; os códigos que mobiliza se estendem até onde a vista alcança, são indetermináveis.

Essas características das redes podem ser aplicadas aos organismos, às tecnologias, aos dispositivos, mas também à subjetividade. Somos uma rede de redes (multiplicidade), cada rede remetendo a outras redes de natureza diversa (heterogênese) em um processo autoreferente (autopoiesis).

O sujeito é um sistema autopoiético e, como todo sistema autopoiético definido por Varela e Maturana, ele se organiza como uma rede auto-referente, que regenera, continuamente por suas interações e transformações, a rede que o produziu, e se constitui como sistema ou unidade concreta no espaço em que existe, especificando o domínio topológico no qual existe como rede. A subjetividade é, como a cognição, o advento, a emergência (enação) de um afeto e de um mundo a partir de suas ações no mundo.

Pensar a subjetividade como autopoiesis nos leva a descrever o saber, a razão, a cognição, a inteligência, não como faculdades de um sujeito, uma vez que eles são dimensões que co-emergem com os universos sociais. Por outro lado, estas "capacidades" que co-emergem com o indivíduo em um processo de auto-engendramento não podem ser vinculadas apenas a seu cérebro, mas a seu corpo, que ultrapassa de longe o seu invólucro corporal e se estende até onde se estendem suas redes sociotécnicas, seus hábitos, seus apegos.

\section{Notas}

1. O presente artigo é parte de uma pesquisa sobre conceito de dispositivo financiada pelo CNPq como bolsa de produtividade em pesquisa intitulado "Do dispositivo do cinema ao cinema do dispositivo".

\section{Referências bibliográficas}

BARTHES, R. S/Z. Rio de Janeiro: Nova Fronteira, 1992.

BAUDRILLARD, J. Simulacros e simulação. Lisboa: Relógio D'Água, 1991.

CHARTIER, R. A ordem dos livros. Brasília: UnB, 1994.

DELEUZE, G. e Guattari, F. Mil platôs. v. 1-5, São Paulo: Ed. 34, 1995. 
DELEUZE, G. Conversações. Rio de Janeiro: 34, 1992.

FOUCAULT, M. Dits et écrits: 1954-1988. Paris: Gallimard, 1994.

GUATTARI, F. Caosmose. Rio de Janeiro: 34, 1992.

GUATTARI, F. Produção de Subjetividade. In: PARENTE, A. (org.) Imagem-máquina. Rio de Janeiro: 341993.

KASTRUP, V. A rede: uma figura empírica da ontologia do presente. In: PARENTE, A. (org.). Tramas da Rede. Novas dimensões filosóficas, estéticas e políticas da comunicação. Porto Alegre, Sulina, 2004.

LATOUR, B. Jamais fomos modernos. Rio de Janeiro: 34, 1993.

LATOUR, B. Redes que a razão desconhece. In: PARENTE, A. (org.). Tramas da Rede. Novas dimensões filosóficas, estéticas e políticas da comunicação. Porto Alegre, Sulina, 2004.

LÉVY, P. As tecnologias da inteligência. Rio de Janeiro: 34, 1993.
LYOTARD, J.F. A condição pós-moderna. Rio de Janeiro: José Olympio, 1990.

LYOTARD, J.F. O inumano. Lisboa: Editorial Estampa, 1989.

NEGRI, T. Exílio. São Paulo: Iluminuras, 2001.

PARENTE, A. Imagem-máquina. Rio de Janeiro: 34, 1993.

PARENTE, A. O virtual e o hipertextual. Rio de Janeiro: Pazulin, 1999.

PARENTE, A. Tramas da Rede. Novas dimensões filosóficas, estéticas e políticas da comunicação. Porto Alegre, Sulina, 2004.

SERRES, M. Atlas. Paris: Albin Michel, 1998.

VIRILIO, P. A máquina de visão. Rio de Janeiro: José Olympio, 1994.

VIRILIO, P. A Inércia polar. Lisboa: Publicações Dom Quichote, 1993.

\section{Sobre o autor}

\section{André Parente}

Doutor, especialista do audiovisual e das novas tecnologias de comunicação. É professor e pesquisador da Escola de Comunicação da Universidade Federal do Rio de Janeiro, onde coordena, desde 1991, o Núcleo de Tecnologia da Imagem (N-imagem). Obteve seu Doutorado em comunicação na Universidade de Paris VIII, onde estudou sob a orientação do filósofo Gilles Deleuze (1982-87). Entre os seus principais livros, destacamos: Imagem-máquina (Ed. 34, 1993); Sobre o cinema do simulacro (Pazulin, 1998); O virtual e o hipertextual (Pazulin, 1999); Narrativa e modernidade. (Papirus, 2000), Redes Sensoriais (com Kátia Maciel, Ed Contra Capa (2003), Tramas da Rede (Ed. Sulinas, 2004), Cinema et Narrativité (L'Harmattan, 2005). 